\title{
Elderly patients and attitudes to having medication deprescribed: a mixed method study in Portuguese primary health care
}

Pedro Augusto Simões ${ }^{1,2}$, Luiz Miguel Santiago ${ }^{3,4,5}$, Beatriz de Oliveira Xavier ${ }^{6,7}$, José Augusto Simões ${ }^{1,8,9}$

\author{
${ }^{1}$ Department of Medical Sciences, University of Beira Interior, Covilhã, Portugal \\ ${ }^{2}$ ARS Centro, USF Pulsar, Coimbra, Portugal \\ ${ }^{3}$ University of Coimbra, Faculty of Medicine, Coimbra, Portugal \\ ${ }^{4}$ CEISUC - Center for Health Studies and Research, Coimbra, Portugal \\ ${ }^{5}$ General Practice/Family Medicine University Clinic, Faculty of Medicine, Coimbra, \\ Portugal \\ ${ }^{6}$ Nursing School of Coimbra, Portugal \\ ${ }^{7}$ UICISA: E-Health Sciences Research Unit: Nursing, Portugal \\ ${ }^{8}$ CINTESIS - Centre for Research in Health Technologies and Service, Porto, Portugal \\ ${ }^{9}$ ARS Centro, Coordination of Medical Residency in General Practice/Family Medicine \\ in the Central Zone, Coimbra, Portugal
}

Submitted: 8 July 2020

Accepted: 21 February 2021

Arch Med Sci

DOI: https://doi.org/10.5114/aoms/133523

Copyright $\odot 2020$ Termedia \& Banach

\section{Abstract}

Introduction: Deprescribing is the process of tapering or stopping medications aiming at improving patient outcomes and optimising current therapy. Some studies have tried to identify which patients will have inappropriate medication deprescribed, but none have found any association with sociodemographic and clinical characteristics, number of prescribed medications or duration of medication. Our aim was to determine Portuguese elderly patients' attitudes and beliefs regarding medication use and their willingness to have regular medications deprescribed.

Material and methods: We conducted a cross-sectional study in triangulation in primary care centres from mainland Portugal and its autonomous regions. We used a random sample of 386 polymedicated older adult patients who answered the questionnaire between October 2018 and February 2019. For the quantitative analysis, we used sociodemographic characteristics, clinical profile and medication. For the qualitative analysis, we studied an included open question by coding participants' answers; common codes were grouped together. A convergent mixed methods design was used.

Results: $74.0 \%$ expressed the belief that medicines were generally beneficial. $19.9 \%$ reported a strong belief that medicines were harmful and $33.4 \%$ that they were overused. $61.8 \%$ were against the idea of deprescribing and $24.6 \%$ were in favour of deprescription. Those against the idea had a lower education level $(p=0.006)$ and a higher number of self-perceived morbidities $(p=0.001)$ than those not against it.

Conclusions: Medication benefits were accepted by the majority of patients who also were against the idea of deprescribing. It is important that doctors are aware of this reality, namely in the primary care setting, addressing the patients' fears and beliefs and making the deprescribing process possible.

Key words: deprescription, aged, polypharmacy, patient acceptance of health care.
Corresponding author: José Augusto Rodrigues Simões

University of Beira Interior Portugal

Phone: +351924406127

E-mail: jars@ubi.pt 


\section{Introduction}

The prevalence of potentially inappropriate medications (PIMs) has been described as $68.6 \%$ of Portuguese elderly patients ( $\geq 65$ years) in the primary care setting [1].

Deprescribing is the process of tapering or stopping medications with the aim of improving patient outcomes and optimizing current therapy [2]. Some studies have been performed in order to identify which patients will have inappropriate medication deprescribed; none found any association between age, gender, education level, general health status, previous attempt of deprescribing the number of medicines or its length of use and the success of the deprescribing process [3-5]. One of the barriers to deprescribing in the primary care setting is the lack of time in the consultation $[6,7]$. Therefore, creating an accurate profile of patients who are willing to have medication deprescribed is critical to improve clinical efficiency.

The Beliefs about Medicines Questionnaire [8] is composed of two sections: the General section (BMQ-General), which assesses more general beliefs about medicines and includes the overall perception of Harm (General-Harm subscale) and Overuse (General-Overuse subscale) of medication; and the Specific section (BMQ-Specific), which assesses beliefs about a particular medication and explores the needs (Specific-Necessity subscale) and concerns (Specific-Concern subscale) perceived about the medication. This questionnaire is cross-culturally validated for the Portuguese population [9].

The aim of this study was to determine Portuguese elderly patients' attitudes and beliefs regarding medication use and their willingness to have regular medications deprescribed. The only previous study about the elderly patients' beliefs regarding medication use was the cross-cultural adaptation of the Beliefs about Medicines Questionnaire into Portuguese [9].

\section{Material and methods}

\section{Study design}

Cross-sectional study-details, definitions and methods were previously published [10]. We adopted a convergent mixed methods design [11]. Secondary analysis of available quantitative and qualitative data was conducted separately as described below, and the findings were triangulated during the interpretation stage $[11,12]$.

The study was performed in agreement with the principles of the Declaration of Helsinki [13] and received ethical approval from the University of Beira Interior and Portuguese healthcare administrative five regions Institutional Ethics Committees. The reporting of this study conforms to the Strengthening the Reporting of Observational Studies in Epidemiology (STROBE) statement [14].

\section{Setting}

The study was carried out in randomly selected primary care health centres in Portugal that agreed to participate from the five mainland Portuguese healthcare administrative regions and two autonomous regions (Madeira and Azores) according to a protocol previously published [10].

\section{Sampling}

Since the prevalence of polypharmacy in the elderly population in Portugal is 77\% [15], we estimated a sample of a minimum 385 patients with polypharmacy for a $95 \% \mathrm{Cl}$ and a maximum precision error of $5 \%$.

Assuming that a general practitioner (GP) would be able to include at least 6 patients, a total of 65 GPs were invited to participate in this study. The GPs were randomly selected from existing files of previous projects' adherent GPs, in other epidemiological studies, for a higher adherence rate.

\section{Data collection procedures}

The invitation of GPs and the recruitment of patients occurred between October 2018 and February 2019. The GPs were individually instructed to give the questionnaire and the informed consent to all elderly patients with polypharmacy, equal to or more than five drugs per day, attending a primary care consultation during 6 randomized consultation days selected for the month after their agreement to collaborate. The GPs were responsible for explaining the study, answering patients' doubts, delivering the questionnaire and the informed consent and collecting them. Exclusion criteria were being acutely unwell in the previous three weeks, recruiting GPs having been instructed to verify whether a sudden disease or acute health condition (such as infectious, painful or inflammatory episodes) medication had been prescribed in such a period of time, and refusal to participate.

\section{Quantitative data collection and analysis}

A questionnaire designed to collect socio-demographic information such as age, gender (male/female), area of residence (the health administrative region), perceived number of chronic health problems and auto-referred number of daily medications was used in the study. We used the Portuguese adapted version of Beliefs about Medicines Questionnaire-General (BMQ-General) [9]. Some researchers were randomly selected to deliver to their participants an extended version of the questionnaire also with the BMQ-Specific 
questionnaire, in order to obtain more detailed information about patients' beliefs about specific medications they were on, since it comprises two scales of assessing personal beliefs about the necessity of prescribed medication for controlling illness and concerns about the potential adverse consequences of medications.

Participants' questionnaires were excluded if any item of BMQ was missing.

\section{Outcome variables}

We calculated mean and median scores for both BMQ scales and sub-scales.

For the BMQ-Specific we created four attitudinal groups regarding medication, as used in previous studies [16, 17]:

- Sceptical (low necessity, high concerns).

- Indifferent (low necessity, low concerns).

- Ambivalent (high necessity, high concerns).

- Accepting (high necessity, low concerns). Statistical analysis was conducted using SPSS V.24.0 and we used a significance level of 0.05 .

\section{Qualitative data collection and analysis}

An open question ("What do you think about stopping some of the medications you are on?") was used in the questionnaire. Two individual investigators coded the participants' answers summarising the content. The common codes features were grouped together. According to the willingness to have medication deprescribed we created four main categories (against, in favour, indecisive and indifferent) and subcategories emerged from the answers. According to the centre for decision of deprescribing, three main categories (the person himself, the doctor and other) were constructed $[18,19]$.

\section{Results}

\section{Characteristics of participants}

The adherence rate of GPs' participation in the study was $47.7 \%(n=31)$, but since each GP on average recruited 13 patients and we obtained 403 elderly patients (386 respected the inclusion criteria) we stopped recruiting GPs for the study.

Of the 386 participants, $59.7 \%$ were female, mean age of 76.7 (95\% Cl: 76.0-77.4) years, and the mean number of drugs per person was 7.3 (95\% Cl: 7.1-7.6) (Table I).

Of the 100 participants who answered the extended version of the questionnaire, $59 \%$ were female, mean age of 80.1 (95\% Cl: 78.5-81.7) years,

Table I. Characteristics of the sample

\begin{tabular}{|c|c|c|c|}
\hline Characteristic & $\begin{array}{l}\text { Total } \\
\%(n)\end{array}$ & $\begin{array}{c}\text { BMQ-Specific responders } \\
\%(n)\end{array}$ & $\begin{array}{l}\text { Open question responders } \\
\%(n)\end{array}$ \\
\hline \multicolumn{4}{|l|}{ Gender: } \\
\hline Women & $59.6(230)$ & $59.0(59)$ & $57.1(177)$ \\
\hline Men & $40.4(156)$ & $41.0(41)$ & $42.9(133)$ \\
\hline \multicolumn{4}{|l|}{ Age [years]: } \\
\hline 65 to 74 & $43.5(168)$ & $28.0(28)$ & $43.5(135)$ \\
\hline$\geq 75$ & $56.5(218)$ & $72.0(72)$ & $56.5(175)$ \\
\hline \multicolumn{4}{|l|}{ Education: } \\
\hline Low level (< 6 years) & $75.1(290)$ & $84.0(84)$ & $76.1(236)$ \\
\hline Medium level (6 to 9 years) & $13.2(51)$ & $10.0(10)$ & $13.5(42)$ \\
\hline High level (> 9 years) & $10.9(42)$ & $6.0(6)$ & $9.4(29)$ \\
\hline Unknown & $0.8(3)$ & $0.0(0)$ & $1.0(3)$ \\
\hline \multicolumn{4}{|c|}{ Perceived number of chronic health problems: } \\
\hline 0 to 2 & $16.8(65)$ & $55.0(55)$ & $21.3(66)$ \\
\hline 3 to 4 & $38.1(147)$ & $19.0(19)$ & $32.9(102)$ \\
\hline 5 to 6 & $27.5(106)$ & $8.0(8)$ & $25.8(80)$ \\
\hline 7 to 8 & $7.5(29)$ & $1.0(1)$ & $8.7(27)$ \\
\hline 9 to 10 & $2.8(11)$ & $0.0(0)$ & $3.5(11)$ \\
\hline$\geq 11$ & $0.8(3)$ & $0.0(0)$ & $1.0(3)$ \\
\hline NA & $6.5(25)$ & $17.0(17)$ & $6.8(21)$ \\
\hline \multicolumn{4}{|l|}{ Number of medications: } \\
\hline 5 to 9 drugs & $79.5(307)$ & $68.0(68)$ & $76.8(238)$ \\
\hline$\geq 10$ drugs & $20.5(79)$ & $32.0(32)$ & $23.2(72)$ \\
\hline
\end{tabular}


and the mean self-reported number of drugs per person was 8.1 (95\% Cl: 7.5-8.7). The subgroup that answered the BMQ-Specific was statistically significantly older $(p=0.005)$ and had a lower number of perceived chronic health problems $(p<0.001)$ than the sample group. There were no statistically significant differences for the other variables in Table I.

\section{$\mathrm{BMQ}$ analysis}

Most participants (74\%) believed that medicines were generally beneficial. However, $19.9 \%$ indicated a strong belief that medicines were harmful and $33.4 \%$ that they were generally overused (Table II).

Analysing the group of 100 participants who answered the extended version, we found similar results for the belief that medicines were harmful (14.0\%) and that they were generally overused (45.0\%).
According to the belief in the need for medication (BMQ-Specific Necessity), 97.0\% agreed for maintaining health (score greater than the scale mid-point), but $45.0 \%$ were concerned about potential adverse consequences of medications (score greater than the scale mid-point). Most of them $(74.0 \%)$ indicated strong beliefs that the benefits of their medication outweighed the risks (the difference between the need and concern scores was positive). When participants were categorised by belief group, the majority were found to be accepting (46.0\%) or ambivalent (44.0\%) (Figure 1).

\section{Participants' views on deprescribing}

In order to obtain the participants' views on deprescribing we asked the open question "What do you think about stopping some of the medications you are on?". From the 386 participants, only $75.9 \%(n=293)$ answered this question. From its

Table II. Patients' beliefs about medicines

\begin{tabular}{|c|c|c|c|}
\hline BMQ subscale & Mean $(95 \% \mathrm{Cl})$ & $P$-value & $\begin{array}{l}\%(n) \text { above the scale } \\
\text { mid-point }\end{array}$ \\
\hline General Overusea: & $11.4(11.1-11.6)$ & & $33.4(129)^{\mathrm{g}}$ \\
\hline Women & $11.2(10.8-11.6)$ & $0.217^{e}$ & $31.7(73)$ \\
\hline Men & $11.5(11.1-12.0)$ & & $35.9(56)$ \\
\hline 65 to 75 years & $11.1(10.7-11.5)$ & $0.306^{\mathrm{e}}$ & $31.5(53)$ \\
\hline$\geq 75$ years & $11.5(11.1-11.9)$ & & $34.9(76)$ \\
\hline General Harma: & $10.3(10.0-10.6)$ & & $19.9(77)^{\mathrm{g}}$ \\
\hline Women & $10.3(9.9-10.8)$ & $0.672^{\mathrm{e}}$ & $22.2(51)$ \\
\hline$\overline{\text { Men }}$ & $10.1(9.6-10.5)$ & & $16.7(26)$ \\
\hline 65 to 75 years & $10.5(10.0-10.9)$ & $0.225^{\mathrm{e}}$ & $23.2(39)$ \\
\hline$\geq 75$ years & $10.1(9.6-10.5)$ & & $17.4(38)$ \\
\hline Necessity ${ }^{b}$ : & $21.3(20.1-22.5)$ & & $97.0(97)^{\mathrm{h}}$ \\
\hline Women & $21.6(20.9-22.3)$ & $0.116^{\mathrm{e}}$ & $96.6(57)$ \\
\hline Men & $20.8(20.0-21.5)$ & & $97.6(40)$ \\
\hline 65 to 75 years & $21.6(20.6-22.6)$ & $0.423^{e}$ & $96.4(27)$ \\
\hline$\geq 75$ years & $21.1(20.5-21.7)$ & & $97.2(70)$ \\
\hline Concern': & $17.5(16.7-18.3)$ & & $45.0(45)^{h}$ \\
\hline Women & $17.3(16.2-18.5)$ & $0.580^{\mathrm{e}}$ & $45.8(27)$ \\
\hline Men & $17.7(16.7-18.8)$ & & 43.9 (18) \\
\hline 65 to 75 years & $17.5(15.5-19.5)$ & $0.984^{\mathrm{e}}$ & $42.9(12)$ \\
\hline$\geq 75$ years & $17.5(16.7-18.3)$ & & $45.8(33)$ \\
\hline $\begin{array}{l}\text { Necessity-concern } \\
\text { differentiald: }^{\text {dif }}\end{array}$ & $3.8(2.9-4.7)$ & & $74.0(74)^{h}$ \\
\hline Women & $4.3(3.0-5.6)$ & $0.171^{f}$ & $76.3(45)$ \\
\hline Men & $3.0(1.9-4.2)$ & & $70.7(29)$ \\
\hline 65 to 75 years & $4.1(2.0-6.2)$ & $0.631^{f}$ & $75.0(21)$ \\
\hline$\geq 75$ years & $3.6(2.7-4.6)$ & & $73.6(53)$ \\
\hline
\end{tabular}

${ }^{a}$ Scale from 4 to 20 where high scores indicate higher agreement. ${ }^{b}$ Scale from 5 to 25 where high scores indicate higher agreement. 'Scale from 6 to 30 where high scores indicate higher agreement. ${ }^{d}$ Scale from -20 to 20 where positive scores indicate patient perceives that

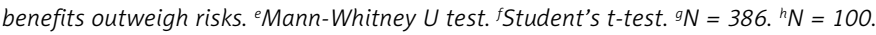


analysis we found that $61.8 \%(n=181)$ of the patients were against the idea of deprescribing. - "I don't think it's possible to stop medicines, I have to take them all." [P327, 89 years].

In favour of the idea were $24.6 \%(n=72)$ of the responders; $7.2 \%(n=21)$ were indifferent;

- "I agree, medicines are bad." [P402, 66 years]

- "It's the doctor who knows." [P21, 71 years]

- "I don't think it's good or bad." [P319, 80 years] and $6.5 \%(n=19)$ were indecisive.

_ "I would like it, but I think they are what support my health." [P105, 74 years]

- "Yes, but I'm afraid." [P131, 78 years]

- "It's hard to answer because I don't know what the effect will be on the clinical level." [P380, 76 years] From the 181 participants who were against deprescription we could subcategorise $55.2 \%(n=$ $100)$ of the answers. Almost half of them (41\%) were against it because of the perception that it would worsen their medical condition;

- "I can't stop because otherwise I will die" [P36, 76 years]

- "There are medications that if I quit my system soon changes, for example cholesterol and tension. If I do not take the inhaler, asthma appears." [P182, 77 years]

Thirty-one percent were against it because of the value they attribute to medicines;

- "I must not stop because they are good for my health" [P35, 66 years]

Others, $18 \%$, because they felt well as they were;

- "I think not. If I feel well, there is no need to take away medications." [P339, 83 years]

Six percent said that they should take it because if it was prescribed by the doctor;

- "In my opinion I trust the doctor and I think he prescribes within my needs as a patient." [P150, 72 years]

and $4 \%$ were against it because they had already tried stopping some medications and it did not go well.

- "I thought so, but I came to the conclusion that I am addicted to medicines." [P15, 82 years]

- "If you stop 2/3 days you will not notice a difference. If it is more days, problems arise." [P70, 75 years]

From the 72 participants who were in favour we could subcategorise $83.3 \%(n=60)$ of the answers. The most common reason was the willingness to reduce the medication list (35\%). Some patients said:

- "I would like them to be reduced. I think it is possible." [P295, 83 years]

- "The less the better." [P333, 93 years]

$33.3 \%$ would agree to stop medication if the doctor told them to;

- "I do not do it. Only with the doctor's indication." [P34, 72 years]

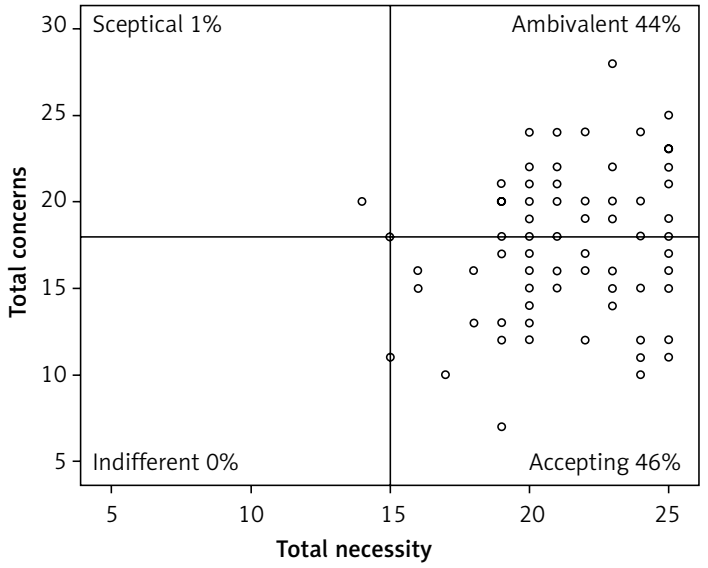

Figure 1. Elderly patients and the idea of having medication deprescribed $(n=100)$

- "If the doctor indicates I have no problem stopping the medication. On my own initiative I exclude the possibility of stopping the medication." [P93, 83 years]

- "I liked it! But I'm scared! But if the doctor proposed, I would accept it." [P104, 88 years]

Twenty percentage if there were side effects or if the medication was ineffective;

- "I agree totally. I think I need to stop it now, because, for example, I sleep a lot now." [P318, 69 years]

- "I agree if the medication is not doing well." [P390, 66 years]

- "Yes, I would like to reduce the number of medicines I take as they cause unwanted effects." [P400, 68 years]

and $11.7 \%$ were in favour of deprescribing because they had already tried and it went well.

- "I do it from time to time when I feel better." [P395, 86 years]

- "Sometimes I forget some because I feel good." [P398, 83 years]

From 190 answers we could deduct where the decision centre about the idea of deprescribing was. In $60.5 \%$ the centre of ideas and feelings about medicines and deprescription was in the patient.

- "There are medicines to stop, others not." [P58, 79 years]

- "I don't want to stop any medication because I need them all." [P301, 86 years]

- "When I am better, I try to reduce them, but sometimes I have to go back to what I was prescribed." [P312, 62 years]

In $39.0 \%$ of the answers, patients put the centre of decision in the doctor and $0.5 \%$ in a third person.

- "Error. I would not do it without talking with the physician.” [P40, 76 years]

- "This opinion I think belongs to the doctor." [P386, 73 years] 
- "Yes, I think I take too many medications, but it depends on the doctor." [P401, 91 years]

- "I was told that I couldn't." [P24, 79 years]

\section{Willingness to have medication deprescribed}

We compared the characteristics of the group against the idea of being deprescribed with those of the group not against being deprescribed (in favour, indifferent and indecisive).

We found no significant differences according to age, gender or number of medications. However, we found that those against being deprescribed had a lower education level $(p=0.006$, mean difference of -1.11 years $(-1.87$ to -0.34$)$ ) and had a higher number of perceived morbidities ( $p=0.001$, mean difference of +0.97 (0.41 to 1.52)) than those not against being deprescribed.

Table III shows the differences in responses between the two groups according to BMQ (General and Specific). We found statistically significant differences in statements regarding the willingness to have medication deprescribed:

- BMQ statement 2 "People who take medicines should stop their treatment for a while every now and again" ( $p<0.001)$ : those against having medication deprescribed mostly disagreeing with the statement and those not against having medication deprescribed agreeing with it;

- BMQ statement 4 "Natural remedies are safer than medicines" ( $p=0.047)$ : those against having medication deprescribed mostly disagreeing with the statement and those not against neither agreeing or disagreeing;

- BMQ-General Overuse ( $p<0.001)$ : those against having medication deprescribed mostly disagreeing that there was overuse of medicines and those not against perceiving overuse of medicines;

- BMQ-General Harm ( $p=0.003)$ : those against having medication deprescribed disagreeing more and those agreeing to having medication deprescribed agreeing more with the sense of harm by medicines.

There were no statistically significant differences between the two groups according to the needs and concerns about medication. However, we found that those against the idea of having medication deprescribed perceived that the benefits of medication outweigh the risks to a higher degree than those not against the idea $(p=0.027$, mean difference $=1.97$ (0.22 to 3.72)).

\section{Discussion}

\section{Strengths of the study}

Combining qualitative and quantitative data from a representative random sample allows a richer analysis for the comprehension of the questions to be studied.

\section{Statement of overall findings}

This study results reveal that there was a strong belief in medication benefits. For $19.9 \%$ a strong belief that medicines were harmful and for 33.4\% medicines were overused was perceived. Our findings concerning the general harm and overuse of the medication were higher than those reported in other studies, namely compared with a study in Ireland [17] reporting that only 3\% of patients believed that the medication was harmful and just over $5 \%$ that it was overused. In relation to the BMQ-Specific, we found that $97 \%$ viewed the medication as necessary and $45 \%$ were concerned about potential adverse consequences, these results being in line with those in Ireland [17]. When participants were categorized by belief group, we found a lower number of participants accepting the medication compared with Clyne et al. (46\% vs. $63.4 \%$ ) but a higher number of ambivalent participants (44\% vs. $32.6 \%)$ [17].

Overall, the literature shows rates of $85-90 \%$ of older adults who are willing to stop one or more medications [5, 20], but according to Turner et al. [5] from $86 \%$ willing to stop only $41 \%$ successfully discontinued their prescription at 6 months after intervention.

No difference in the willingness to have medication deprescribed according to age matches the literature [3-5]. However, some studies have found that older adults notice differences between stopping preventive medications and feeling relief of symptoms. They perceived clear efficacy for symptomatic relief medicines since they notice the symptoms anew when they reduce or stop medicines. However, with prophylactic or specific treatment medicines, the patients are not so easily aware of the medicines' benefits, making them more prone to stop them [21-23].

Patient's gender does not seem to affect the willingness to have medication deprescribed, and this is also in line with previous studies [3-5].

According to the patient's willingness to have medications deprescribed, we found a rise with the increased educational level, as found by previous studies [3-5]. One possible explanation is that people with a higher educational level are more knowledgeable and able to make a critical assessment of drugs, knowing that they have benefits and risks and that, sometimes, risks may outweigh their benefits. However, most of the participants in both groups did not have more than 6 years of education, so we cannot extrapolate to the other higher education levels.

Patients with a lower number of perceived morbidities seem to have a stronger willingness 
Table III. Comparison of BMQ according to the willingness to have medication deprescribed

\begin{tabular}{|c|c|c|c|c|c|c|c|}
\hline BMQ & $\begin{array}{l}\text { Willingness to } \\
\text { have medication } \\
\text { deprescribed }\end{array}$ & $\begin{array}{c}\text { Strongly } \\
\text { disagree } \\
\%(n)\end{array}$ & $\begin{array}{c}\text { Disagree } \\
\%(n)\end{array}$ & $\begin{array}{c}\text { Uncertain } \\
\%(n)\end{array}$ & $\begin{array}{l}\text { Agree } \\
\%(n)\end{array}$ & $\begin{array}{l}\text { Strongly } \\
\text { agree } \\
\%(n)\end{array}$ & $\begin{array}{c}P \text {-value } \\
\left(\chi^{2}\right)\end{array}$ \\
\hline \multirow[t]{2}{*}{ G1 } & Against & $18.2(33)$ & $55.2(100)$ & $12.7(23)$ & 9.4 (17) & $4.5(8)$ & 0.177 \\
\hline & Not against & $2.7(3)$ & $12.5(14)$ & $17.0(19)$ & $58.9(66)$ & $8.9(10)$ & \\
\hline \multirow[t]{2}{*}{ G2 } & Against & $22.0(40)$ & $37.7(68)$ & $15.4(28)$ & $19.9(36)$ & $5.0(9)$ & $<0.001$ \\
\hline & Not against & $6.3(7)$ & $29.5(33)$ & $14.3(16)$ & $40.1(45)$ & $9.8(11)$ & \\
\hline \multirow[t]{2}{*}{ G3 } & Against & $11.6(21)$ & $27.0(49)$ & $14.4(26)$ & $36.5(66)$ & $10.5(19)$ & 0.308 \\
\hline & Not against & $4.4(5)$ & $28.6(32)$ & $13.4(15)$ & $42.9(48)$ & $10.7(12)$ & \\
\hline \multirow[t]{2}{*}{ G4 } & Against & $15.5(28)$ & $30.4(55)$ & $27.0(49)$ & $19.9(36)$ & $7.2(13)$ & 0.047 \\
\hline & Not against & $5.3(6)$ & $30.4(34)$ & $25.0(28)$ & $30.4(34)$ & $8.9(10)$ & \\
\hline \multirow[t]{2}{*}{ G5 } & Against & $32.0(58)$ & $53.1(96)$ & $6.6(12)$ & $6.1(11)$ & $2.2(4)$ & 0.145 \\
\hline & Not against & $24.1(27)$ & $52.7(59)$ & $14.3(16)$ & $8.0(9)$ & $0.9(1)$ & \\
\hline \multirow[t]{2}{*}{ G6 } & Against & $31.5(57)$ & $47.5(86)$ & $10.5(19)$ & $5.0(9)$ & $5.5(10)$ & 0.206 \\
\hline & Not against & $26.8(30)$ & $47.3(53)$ & $11.6(13)$ & $11.6(13)$ & $2.7(3)$ & \\
\hline \multirow[t]{2}{*}{ G7 } & Against & $8.3(15)$ & $18.2(33)$ & $25.4(46)$ & $36.5(66)$ & $11.6(21)$ & 0.058 \\
\hline & Not against & $2.7(3)$ & $25.0(28)$ & $16.1(18)$ & $40.1(45)$ & $16.1(18)$ & \\
\hline \multirow[t]{2}{*}{ G8 } & Against & $7.7(14)$ & $38.2(69)$ & $26.5(48)$ & $21.0(38)$ & $6.6(12)$ & 0.056 \\
\hline & Not against & $1.8(2)$ & $29.6(33)$ & $37.5(42)$ & $22.3(25)$ & 8.9 (10) & \\
\hline \multirow{2}{*}{$\begin{array}{l}\text { Overuse (G1, } \\
\text { G4, G7, G8) }\end{array}$} & Against & - & 59.7 (108) & $14.3(26)$ & $26.0(47)$ & - & $<0.001$ \\
\hline & Not against & - & $40.2(45)$ & $10.7(12)$ & $49.1(55)$ & - & \\
\hline \multirow{2}{*}{$\begin{array}{l}\text { Harm (G2, G3, } \\
\text { G5, G6) }\end{array}$} & Against & - & 72.9 (132) & $17.2(31)$ & $9.9(18)$ & - & 0.003 \\
\hline & Not against & - & $64.3(72)$ & $12.5(14)$ & $23.2(26)$ & - & \\
\hline \multirow[t]{2}{*}{ N1 } & Against & - & $0(0)$ & $4.4(2)$ & $95.6(43)$ & - & 0.641 \\
\hline & Not against & - & $1.8(1)$ & $5.5(3)$ & $92.7(51)$ & - & \\
\hline \multirow[t]{2}{*}{ N2 } & Against & - & $2.2(1)$ & $2.2(1)$ & $95.6(43)$ & - & 0.238 \\
\hline & Not against & - & $5.5(3)$ & $9.1(5)$ & $85.4(47)$ & - & \\
\hline \multirow[t]{2}{*}{ N3 } & Against & - & $0(0)$ & $2.2(1)$ & $97.8(44)$ & - & 0.144 \\
\hline & Not against & - & $3.6(2)$ & $9.1(5)$ & $87.3(48)$ & - & \\
\hline \multirow[t]{2}{*}{ N4 } & Against & - & $0(0)$ & $4.4(2)$ & $95.6(43)$ & - & 0.174 \\
\hline & Not against & - & $5.5(3)$ & $9.1(5)$ & $85.4(47)$ & - & \\
\hline \multirow[t]{2}{*}{ N5 } & Against & - & $0(0)$ & $6.7(37)$ & $93.3(42)$ & - & 0.425 \\
\hline & Not against & - & $3.6(2)$ & $5.5(3)$ & $90.9(50)$ & - & \\
\hline \multirow{2}{*}{$\begin{array}{l}\text { Total } \\
\text { necessity }\end{array}$} & Against & - & $0(0)$ & $0(0)$ & $100(45)$ & - & 0.354 \\
\hline & Not against & - & $1.8(1)$ & $3.6(2)$ & $94.6(52)$ & - & \\
\hline \multirow[t]{2}{*}{$\mathrm{C} 1$} & Against & - & $33.3(15)$ & $4.4(2)$ & $62.3(28)$ & - & 0.487 \\
\hline & Not against & - & $32.7(18)$ & $10.9(6)$ & $56.4(31)$ & - & \\
\hline \multirow[t]{2}{*}{$C 2$} & Against & - & $46.7(21)$ & $4.4(2)$ & $48.9(22)$ & - & 0.308 \\
\hline & Not against & - & 34.5 (19) & $10.9(6)$ & $54.6(30)$ & - & \\
\hline \multirow[t]{2}{*}{ C3 } & Against & - & $28.9(13)$ & $6.7(3)$ & $64.4(29)$ & - & 0.824 \\
\hline & Not against & - & 34.5 (19) & $5.5(3)$ & $60.0(33)$ & - & \\
\hline \multirow[t]{2}{*}{ C4 } & Against & - & $84.4(38)$ & $6.7(3)$ & $8.9(4)$ & - & 0.409 \\
\hline & Not against & - & $76.3(42)$ & $5.5(3)$ & $18.2(10)$ & - & \\
\hline \multirow[t]{2}{*}{ C5 } & Against & - & $44.4(20)$ & $4.5(2)$ & $51.1(23)$ & - & 0.284 \\
\hline & Not against & - & 34.6 (19) & $12.7(7)$ & $52.7(29)$ & - & \\
\hline \multirow[t]{2}{*}{ C6 } & Against & - & $80.0(36)$ & $6.7(3)$ & $13.3(6)$ & - & 0.807 \\
\hline & Not against & - & $74.5(41)$ & $9.1(5)$ & $16.4(9)$ & - & \\
\hline Total concerns & Against & - & $51.1(23)$ & $4.4(2)$ & $44.5(20)$ & - & 0.666 \\
\hline & Not against & - & $43.6(24)$ & $10.9(6)$ & $45.5(25)$ & - & \\
\hline
\end{tabular}

G1 - "Doctors use too many medicines"; G2 - "People who take medicines should stop their treatment for a while every now and again"; G3 - "Most medicines are addictive"; G4 - "Natural remedies are safer than medicines"; G5 - "Medicines do more harm than good"; G6 - "All medicines are poisons"; G7 - "Doctors place too much trust in medicines"; G8 - "If doctors had more time with patients they would prescribe fewer medicines"; N1 - "My health, at present, depends on these medicines"; N2 - "My life would be impossible without these medicines"; N3 - "Without these medicines I would be very ill"; N4 - "My health in the future will depend on these medicines"; N5 - "These medicines protect me from becoming worse"; C1 - "Having to take medicines worries me"; C2 - "I sometimes worry about long-term effects of these medicines"; C3 - "These medicines are a mystery to me"; C4 - "These medicines disrupt my life"; C5 - "I sometimes worry about becoming too dependent on these medicines"; 6 - "These medicines give me unpleasant side effects." 
to have medication deprescribed. Our findings do not corroborate those from previous studies [3-5] that did not find any association between self-reported health and the success of being deprescribed. One possible explanation is that, as the person does not feel so sick, he does not perceive the need to take some of the medications, so is more inclined to stop it.

No difference was found in the willingness to have medication deprescribed according to the number of regular medications, and this is in line with the literature [3-5]. Therefore, more than the number of medicines a patient is taking, it is possibly the patient's view of medications that influences the willingness to have medication deprescribed.

Patient's willingness to have medication deprescribed increases with higher agreement with BMQ-General Overuse, namely with statement number 4 "Natural remedies are safer than medicines". This is reflected in some answers to the open question "What do you think about stopping some of the medications you are on?" - namely in those who want to be deprescribed. This could be due to general dislike of taking medications, including feeling that medications are "unnatural", wanting to be more in control of the treatment and, for patients taking psychiatric medication, the desire to be "normal" and thus reducing the stigma associated with medication use [24]. We can use these findings to help in the deprescription of potentially inappropriate medication (those whose risks outweigh benefits, those with no clear indication or those that are not effective). A study found that patients' belief in the importance of medications is poorly correlated with their GPs' belief in their importance, highlighting the need for continuous dialogue between doctors and patients [25]. Therefore, doctors need to be careful that patients do not replace scientifically studied drugs with other, untested substances, whose effects and interactions may still be unknown.

Patient's willingness to have medication deprescribed also increases with higher agreement with BMQ-General Harm, namely with statement number 2 "People who take medicines should stop their treatment for a while every now and again". Compared with the answers to the open question "What do you think about stopping some of the medications you are on?", we found that patients who felt they were having side effects from the medications, or that they were ineffective, and those who had already tried successfully to stop taking medications, were more willing to have medications deprescribed. This can make some patients stop or think about stopping some of their medications for a period of time when they feel better. As mentioned before, patients' beliefs in the importance of medications correlate poorly with their GPs' belief [25], and sometimes it is difficult for them to perceive the efficacy of medications, namely the ones prescribed for prophylactic or specific treatable conditions [21-23].

According to Reeve et al. [24] one of the enablers of deprescribing is the fear of addiction, namely in those affecting the nervous system. However, we did not find differences according to statement number 3 "Most medicines are addictive" of BMQ-General.

We concluded from the answers that most patients think the decision about being deprescribed lies with themselves and not with their doctors (60.5\% vs. $39.0 \%)$. This does not match other studies where most participants reported that they would like to discontinue one or more of their drugs if their doctor told them that they could do so $[6,26,27]$. A Danish survey [26] found that $85 \%$ of the participants would be willing to stop one or more of their regular medications if their doctor said it was possible. They also found that half of the participants preferred being deprescribed for one or more of their drugs if followed by a healthcare professional in consultation, and the other half of the participants would have liked phone or email follow-up. Another study [28] found that several patients did not know which medications they took and what their indications were because they did not give it any importance, as they had complete trust in the responsible healthcare professionals. Still some studies have found that, in addition to the high interest in stopping medications, a significant number of patients refused to undergo deprescribing when it was proposed [29-31]. This means that if patients lack sufficient health literacy, they cannot make informed health decisions, they feel powerless, assume a passive attitude, and become dependent on their doctor's judgement. Thus, when their GP renews the prescription, they see it as a sign that they need to continue taking it [24], as expressed by some of the participants as the reason for rejecting the idea of being deprescribed. Interpersonal trust (between patient and clinician) is a key element of the doctor-patient relationship, especially as regards taking medicines, one particularly valued by older patients [17, 21, 24, 32-34]. So, doctor's knowledge about medicines is a key subject in deprescribing, as it is in the prescribing process.

However, further studies are needed to better understand the reason why older adults consider that the responsibility for making a decision lies with them and what the reasons for that are (e.g., lack of information? Fear? Results not consistent with what they expect?) in order to increase the success of the deprescription.

Participants had to deliver their questionnaire to their doctor, which may have influenced some responses due to fear of doctor evaluation, 
even though the questionnaires were returned in a closed envelope to be sent to the investigation team.

Not all participants answered the BMQ-Specific, and this subgroup was statistically older and had a lower number of perceived chronic health problems than the sample, so the strength is lower and caution is needed when interpreting these results.

The presented themes emerged from open answers, which do not provide so much information about the patient's perspective as would result from an interview.

We found a limited number of studies comparing elderly patients according to their desire to be deprescribed with the socio-demographic characteristics. Some studies selected mainly older adults already willing to have medication deprescribed and compared those who successfully did it to those who did not succeed. Other studies only reported qualitative results or compared the desire to be deprescribed only using scales, namely BMQ and PATD questionnaires.

In conclusion, this study found a strong belief in medication benefits. It was also observed that the majority $(61.8 \%)$ of the participants were against the idea of being deprescribed.

The categorization of the belief group shows that most of the participants were either accepting of medication or ambivalent. We also found that most participants were against the idea of deprescribing, the most common reasons being the fear of worsening their medical situation, and the value attributed to medicines. The factors related to being against the idea of deprescribing were lower education level and a worse perception of health.

In this study, a group of patients believed that stopping medication should be their own decision. Such a finding requires reflection on the importance of trust and openness for an ethical dialogue relationship. Doctors need to adequately address the burden of patients' medication and be skilful and competent for patient enablement and empowerment if patient centred medicine is to be practised.

It is important that doctors are aware of (the specificity of the contexts and of its consultants, namely in the holistic primary care setting, in order to address the patients' fears, beliefs, expectations and desires according to the explained best practice.

\section{Acknowledgments}

The authors thank Joana Sousa, Maria João Ribeiro, José Baptista Pereira, Sabrina Pedone, Isabel Tadeu, Joana Henriques, Filomena Campos Xavier, Fernando Pereira Bento, Cláudia Bessa, Margarida
Guimarães, Margarida Fontoura, Marli Loureiro, Manuel Geraldes, Letícia Furtado, Fernando Albuquerque, Sónia Batista, Ana Trindade, Clara Jasmins, Margarida Barros Henriques, Cátia Valente, Rita Viegas, Anaisa Silva, Valeriya Real, Catarina Bica, Mariana Capela, Antonietta Denaro, Marta Bragança, Teresa Ventura, Alice Magalhães, Tiago Mendes, Nivalda Pereira e Pedro Pereira for their participation in the data collection, and Maria Rovisco for the English editing.

\section{Conflict of interest}

The author declare no conflict of interest.

\section{References}

1. Simões PA, Santiago LM, Maurício K, Simões JA. Prevalence of potentially inappropriate medication in the older adult population within primary care in Portugal: a nationwide cross-sectional study. Patient Prefer Adherence 2019; 13: 1569-76.

2. Scott IA, Anderson K, Freeman CR, Stowasser DA. First do no harm: a real need to deprescribe in older patients. Med J Aust 2014; 201: 390-2.

3. Tannenbaum C, Martin P, Tamblyn R, Benedetti A, Ahmed S. Reduction of inappropriate benzodiazepine prescriptions among older adults through direct patient education: the EMPOWER cluster randomized trial. JAMA Intern Med 2014; 174: 890-8.

4. Martin P, Tamblyn R, Benedetti A, Ahmed S, Tannenbaum $C$. Effect of a pharmacist-led educational intervention on inappropriate medication prescriptions in older adults: the D-PRESCRIBE randomized clinical trial. J Am Med Assoc 2018; 320: 1889-98.

5. Turner JP, Martin P, Zhang YZ, Tannenbaum C. Patients beliefs and attitudes towards deprescribing: can deprescribing success be predicted? Res Soc Adm Pharm 2020; 16: 599-604.

6. Palagyi A, Keay L, Harper J, Potter J, Lindley RI. Barricades and brickwalls: a qualitative study exploring perceptions of medication use and deprescribing in long-term care. BMC Geriatr 2016; 16: 15.

7. Djatche L, Lee S, Singer D, Hegarty SE, Lombardi M, Maio $\mathrm{V}$. How confident are physicians in deprescribing for the elderly and what barriers prevent deprescribing? J Clin Pharm Ther 2018; 43: 550-5.

8. Horne R, Weinman J, Hankins M. The beliefs about medicines questionnaire: the development and evaluation of a new method for assessing the cognitive representation of medication. Psychol Heal 1999; 14: 1-24.

9. Salgado T, Marques A, Geraldes L, Benrimoj S, Horne R, Fernandez-Llimos F. Cross-cultural adaptation of the Beliefs about Medicines Questionnaire into Portuguese. Sao Paulo Med I 2013; 131: 88-94.

10. Simões PA, Santiago LM, Simões JA. Deprescribing in primary care in Portugal (DePil17-20): a three-phase observational and experimental study protocol. BMJ Open 2018; 8: e019542.

11. Creswell J, Clark V. Designing and Conducting Mixed Methods Research. Thousand Oaks, Calif: SAGE Publications 2007.

12. O'Cathain A, Murphy E, Nicholl J. Three techniques for integrating data in mixed methods studies. BMJ 2010; 341: c4587. 
13. General Assembly of the World Medical Association. World Medical Association Declaration of Helsinki: ethical principles for medical research involving human subjects. J Am Coll Dent 2014; 81: 14-8.

14. von Elm E, Altman DG, Egger M, Pocock SJ, Gøtzsche PC, Vandenbroucke JP, Initiative $S$. The Strengthening the Reporting of Observational Studies in Epidemiology (STROBE) statement: guidelines for reporting observational studies. J Clin Epidemiol 2008; 61: 344-9.

15. Simões PA, Santiago L, Simões JA. Prevalence of polypharmacy in the older adult population within primary care in Portugal: a nationwide cross-sectional study. Arch Med Sci 2020. doi:10.5114/aoms.2020.93537.

16. Menckeberg TT, Bouvy ML, Bracke M, et al. Beliefs about medicines predict refill adherence to inhaled corticosteroids. J Psychosom Res 2008; 64: 47-54.

17. Clyne B, Cooper JA, Boland F, Hughes CM, Fahey T, Smith SM. Beliefs about prescribed medication among older patients with polypharmacy: a mixed methods study in primary care. Br J Gen Pract 2017; 67: e507-18.

18. Gibbs G. Thematic coding and categorizing. In: Analyzing qualitative data. London, England: SAGE Publications, Ltd; 2007: 38-55.

19. Silver C, Lewins A. Qualitative Coding in Software: Principles and Processes. In: Using Software in Qualitative Research: A Step-by-Step Guide Second Edition ed. London, England: SAGE Publications Ltd; 2014; 158-85.

20. Reeve E, Wiese MD, Hendrix I, Roberts MS, Shakib S. People's attitudes, beliefs, and experiences regarding polypharmacy and willingness to deprescribe. J Am Geriatr Soc 2013; 61: 1508-14.

21. Krska J, Morecroft CW, Poole H, Rowe PH. Issues potentially affecting quality of life arising from long-term medicines use: a qualitative study. Int J Clin Pharm 2013; 35: 1161-9.

22. Pound P, Britten N, Morgan M, et al. Resisting medicines: a synthesis of qualitative studies of medicine taking. Soc Sci Med 2005; 61: 133-55.

23. Elliott RA, Ross-Degnan D, Adams AS, Safran DG, Soumerai SB. Strategies for coping in a complex world: adherence behavior among older adults with chronic illness. J Gen Intern Med 2007; 22: 805-10.

24. Reeve E, To J, Hendrix I, Shakib S, Roberts MS, Wiese MD. Patient barriers to and enablers of deprescribing: a systematic review. Drugs Aging 2013; 30: 793-807.

25. Sidorkiewicz S, Tran VT, Cousyn C, Perrodeau E, Ravaud $P$. Discordance between drug adherence as reported by patients and drug importance as assessed by physicians. Ann Fam Med 2016; 14: 415-21.

26. Schiøtz ML, Frølich A, Jensen AK, et al. Polypharmacy and medication deprescribing: a survey among multimorbid older adults in Denmark. Pharmacol Res Perspect 2018; 6: e00431.

27. Kalogianis MJ, Wimmer BC, Turner JP, et al. Are residents of aged care facilities willing to have their medications deprescribed? Res Soc Adm Pharm 2016; 12: 784-8.

28. Todd A, Holmes H, Pearson S, et al. "I don't think I'd be frightened if the statins went": a phenomenological qualitative study exploring medicines use in palliative care patients, carers and healthcare professionals. BMC Palliat Care 2016; 15: 13.

29. Williams ME, Pulliam CC, Hunter R, et al. The short-term effect of interdisciplinary medication review on function and cost in ambulatory elderly people. J Am Geriatr Soc 2004; 52: 93-8.

30. Beer C, Loh PK, Peng YG, Potter K, Millar A. A pilot randomized controlled trial of deprescribing. Ther Adv drug Saf 2011; 2: 37-43.
31. Potter K, Flicker L, Page A, Etherton-Beer C. Deprescribing in frail older people: a randomised controlled trial. PLoS One 2016; 11: e0149984.

32. Ridd M, Shaw A, Lewis G, Salisbury C. The patient-doctor relationship: a synthesis of the qualitative literature on patients' perspectives. Br J Gen Pract 2009; 59: e116-33.

33. Berkelmans PG, Berendsen AJ, Verhaak PF, Van Der Meer K. Characteristics of general practice care: what do senior citizens value? A qualitative study. BMC Geriatr 2010; 10: 80.

34. Andersson Sundell K, Jönsson AK. Beliefs about medicines are strongly associated with medicine-use patterns among the general population. Int I Clin Pract 2016; 70: 277-85. 